\title{
Exploring household dynamics: the reciprocal effects of parent and child characteristics
}

Lidia Panico, Institut National d'Etudes Démographiques, Paris, France

lidia.panico@ined.fr

Laia Bécares, University of Manchester, UK

Elizabeth A Webb, University College London, UK

(Received July 2013 Revised December 2013)

DOI: http://dx.doi.org/10.14301/llcs.v5i1.259

\section{Abstract}

A burgeoning line of literature has shown there are strong effects of maternal mental health on child socio-emotional development (Cummings \& Davies, 1994; Downey \& Coyne, 1990; Mensah \& Kiernan, 2010; Smith, 2004). This literature is often based on the examination of dyadic relationships, where maternal mental health is hypothesised to have an effect on child development and well-being, and the mother-child relationship is examined in isolation of other household relationships. This may also be true in clinical practice: while family dynamics are often considered when treating children for behavioural problems or other psychological symptoms, this is often not the case when the parents are treated. However, household dynamics are complex, and other household members may have an effect both on the well-being of the mother and the child. Furthermore, children's characteristics can also have a feedback effect on their parents' outcomes. While the literature often concentrates on the effects of parents' characteristics on child outcomes, the reverse might also occur. In this paper, we employ a structural equation model with cross lagged effects, to understand the reciprocal relationships between the mother's mental health, the child socio-emotional development, and the quality of the parental relationship. Analyses were conducted using longitudinal data from the Millennium Cohort Study, a prospective national birth cohort of children born in the UK in 2000-2001. The Millennium Cohort Study has a wealth of information on the socio-economic background of the household, and has collected data on the mother's mental health, the quality of the parents' relationship, and the children's socio-emotional development. In this work we look at data relating to the pre-school age, a crucial developmental age which has often been missing from the literature.

Keywords: reciprocal influences; family effects; parent-child effects; child development

\section{Maternal mental health and child well- being}

Mental health problems affect more than $25 \%$ of all people at some time in their lives, and rates of diagnosis are increasing (World Health Organization, 2001). Mental health issues have been found to be particularly prevalent in parents of young children. Oates (1997) found that a quarter of female patients newly referred to psychiatric services in the UK were caring for a child under the age of five, and that a similar proportion of adults with a diagnosis of schizophrenia were living in households with children aged under 16. Overall, $60 \%$ of adults with serious chronic mental illness had children under 16 (Oates, 1997). There are few statistics quantifying this phenomenon from the child's perspective. Using a number of British national surveys on psychiatric disorders and 2001 Census figures of the numbers of dependent children by household type, Gould (2006) calculated that there are just over 1.25 million children in England and Wales living with parents or carers who have a mental health problem. 
There is a longstanding recognition and concern that parental mental health difficulties can impact on children's development (e.g. Downey \& Coyne, 1990; Smith, 2004). The negative impact of maternal depression (the most studied parental mental health problem) on child development has been found for children from infancy to adolescence; the association has been observed in both clinic and community populations, and in a number of different countries and cultures. It is apparent in a wide range of child outcomes such as language development, behaviour, social and emotional competence, sleeping problems, and physical health (Cleaver, Unell, \& Aldgate, 1999; Cummings \& Davies, 1994; S. H. Goodman \& Gotlib, 1999; Hay et al., 2001; Smith, 2004). The effects appear to be both concurrent and longitudinal (Rothbaum \& Weisz, 1994; Waschbusch, 2002). A "parent effects" model, in which conflictual/negative parenting styles cause and/or exacerbate child problems, has traditionally been cited as responsible for this association (Collins, Maccoby, Steinberg, Hetherington, \& Bornstein, 2000; Maccoby, 2000). This is supported by research which shows that, for example, improving parents' discipline strategies leads to a reduction in children's externalizing problems (Dishion \& Kavanagh, 2000).

There are indications that the experience of maternal mental health problems has a larger impact on child behavioural outcomes than either cognitive or educational problems. It has been estimated that children of depressed parents are between two and five times more likely to develop behavioural problems than children whose parents are not depressed, with up to $40 \%$ of children of depressed parents presenting behavioural or emotional problems (Cummings \& Davies, 1994). In addition to concurrent impacts, there are long-term associations. A longitudinal study that conducted a 10-year follow-up investigation of children of depressed parents found a threefold increase in depression, and an even greater increase in the likelihood of developing alcohol dependence or panic disorders, compared to children of non-depressed parents (Weissman, Warner, Wickramaratne, Moreau, \& Olfson, 1997).

These relationships have been tested recently in young British children. Mensah \& Kiernan (2010) found poorer outcomes for a range of cognitive, social and emotional problems among children whose parents reported psychological distress compared to children whose parents did not report distress. Although parents' socio-economic resources mediated some of these effects, an independent effect of mother's psychological distress was retained (Mensah \& Kiernan, 2010). Persistent maternal distress was particularly shown to increase the risk of behavioural problems among 3 year olds (Kiernan \& Mensah, 2009).

Mental health difficulties frequently co-occur with unemployment (Bartley, 1994), socioeconomic deprivation and financial difficulties (Hudson, 2005; R. Jenkins et al., 2008), family instability, early parenthood and low education (Kiernan \& Pickett, 2006). Socio-economic adversity also has a strong influence on early childhood development (see for example reviews by the National Institute of Child Health and the Human Development Early Childcare Network, 2005, and Shonkoff \& Phillips, 2000; and Kiernan \& Huerta, 2008, and Kiernan \& Mensah, 2009 for British examples). Socioeconomic adversity may thus be an important mediator between parents' mental health difficulties and poorer child development.

There are a number of proximate mechanisms through which maternal depression can impact on child well-being, such as increased household chaos, or the quality of the parenting the parent can provide to the child. In a meta-analysis of 46 observational studies, Lovejoy and colleagues (2000) concluded that depressed mothers of infants and young children were more hostile and irritable, more disengaged, and registered lower rates of play and other positive social interactions. Schoon and colleagues have shown that the impact of persistent financial hardship on child outcomes is partially mediated by maternal distress, which affects the quality of parent-child interactions and the provision of a stimulating home environment (Schoon, Hope, Ross, \& Duckworth, 2010).

Most previous research has focused on the impact of maternal depression on child outcomes and not vice-versa; in fact it has often been limited to this. There is some limited literature on the effects of child characteristics on maternal well-being. This tends to focus on specific populations, notably children with disabilities (Hauser-Cram et al., 2001), and especially with developmental disabilities (Olsson \& Hwang, 2001; Singer \& Floyd, 2006). There is, however, growing evidence that a dual child-to-parent effect may also exist in the general population: child maladjustment has been shown to 
influence parents' relationships with one another (Belsky \& Rovine, 1990; Leerkes \& Crockenberg, 2002; Papousek \& von Hofacker, 1998) and parents' own psychological functioning (Ge, Conger, Lorenz, Shanahan, \& Elder Jr, 1995).

Support for a "child effects" models comes from studies such as that carried out by Anderson, Lytton and Romney (1986), in which the authors observed children with conduct disorder problems and their mothers, during play and structured tasks. They found that, when playing with children who did not have conduct problems, mothers of children with conduct problems did not differ from mothers of non-problem children in commands and negative and positive behaviours. However, all mothers responded negatively and gave more commands when playing with children with conduct problems. They therefore concluded that maladaptive interactions between children with conduct problems and their mothers were driven mainly by the child. Similarly, child effects have also been demonstrated during drug treatment experiments: Barkley and Cunningham (1979) found that when the behaviour of non-attentive and non-compliant children was improved through stimulant drugs, the motherchild interactions nearly normalised.

However, one of the cornerstones of contemporary thinking about parenting is the idea of reciprocity in parent-child relationships (Maccoby, 2003), implying that both parent and child effects are at play. Such a reciprocal model has implications for the aetiology, maintenance, assessment, and treatment of psychological and behavioural problems (Downey \& Coyne, 1990). Much of the work exploring reciprocal effects has been based on small, often community-based samples. Few studies have attempted to establish simultaneous models that test the reciprocal relationship between maternal mental well-being and child adjustment problems in a larger, general population. Exceptions include Elgar and colleagues (2003), who used cross-lagged correlations and regressions to examine temporal relations between maternal depressive symptoms and three domains of child functioning: hyperactivity, aggression, and emotional problems in a national sample of Canadian children aged 4-11 years. They found that maternal depression increased the risk of adjustment problems in children, and vice versa, with the mother's effect appearing to be the antecedent.
Furthermore, other actors are often not considered when estimating the relationship between maternal depression and child outcomes. Restricting the analysis to the dyadic pair of mother-child is limiting, as it excludes the influence of other potentially important household members, such as other parents, siblings and other cohabiting adults such as grandparents. Father interactions and father characteristics are increasingly recognized as also being important for child development (Lamb, 2004; Tamis-LeMonda, Shannon, Cabrera, \& Lamb, 2004), and father characteristics may in fact play a moderating role in the effect of maternal depression on child outcomes such as behaviour (Mezulis, Hyde, \& Clark, 2004). While some previous literature has found limited direct effects of father characteristics when added to a mother-child model, how we consider the father vis-à-vis young children may be important. For example, in Conger's classic model of the effects of family stress on children, the father's mental well-being often does not remain significant when modelled alongside maternal mental well-being and relationship quality on child wellbeing, however relationship conflict (to which the father clearly contributes) does (Conger et al., 1992). As young children may be more often looked after by their mothers, their experience of paternal well-being might be manifested, from their perspective, through interactions with the mother. There is a large literature showing that parental conflict has an impact on outcomes such as child behaviour, externalizing problems and peer relations (Benzies, Harrison, \& Magill-Evans, 2004; J. Jenkins, Simpson, Dunn, Rasbash, \& O'Connor, 2005; Katz \& Gottman, 1993; Katz \& Woodin, 2002; Najman et al., 1997).

Few models attempt to bring together a number of actors in explaining the dynamics within the household, and quantitative analyses of large population-based samples have been limited. Furthermore, while these types of models have been used to study other aspects of family dynamics (for example, adolescent depression, marital conflict over child rearing and marital dissatisfaction (Cui, Donnellan, \& Conger, 2007), marital conflict and siblings behaviour (Jenkins et al., 2005)), few have focused on maternal depression and child difficulties. Those that have were restricted to small samples and related to older children. Ge and colleagues used cross-lagged models with three waves of panel data that were collected over 2 years from 
368 parent-child dyads (Ge et al., 1995). Both parents and children provided self-report data on symptoms of depression, anxiety, and hostility. They found that parent and adolescent distress were reciprocally related over time after earlier symptoms were statistically controlled. More recently, Steele, Rasbash \& Jenkins (2013) used the Avon Brothers and Sisters Study, a study of 235 families within ALSPAC (Avon Longitudinal Study of Parents and Children) birth cohort to test the reciprocal lagged effects of maternal depression and siblings' delinquency scores. They found that while the mother's depression did not have a lagged effect on boys' delinquency 2 years later, higher maternal depression was associated with a lower delinquency score among girls, controlling for the child's prior level of delinquency. There was, however, no feedback effect: there was no association between child delinquency and change in maternal depression. The model also tested for sibling effects, however once family-level random effects were included there was no evidence that sibling delinquency predicted the child's delinquency 2 years later (Steele, Rasbash, \& Jenkins, 2012).

\section{Conceptual model}

The present study extends earlier research by proposing that early childhood difficulties will be reciprocally linked with maternal mental distress and the functioning of the parental dyad. The conceptual model therefore attempts to depict relationships between the 3 key variables (maternal psychological distress, child behaviour, and parental relationship quality) at 2 time points. The model is organised in a temporal fashion, taking into account the longitudinal nature of the data, with variables collected at age 3 conceptualised to have an effect on variables at age 5 (see Figure 1). Figure 1 presents a cross-lagged auto-regressive model, a model well-suited for testing hypotheses related to reciprocity and mutual influence (Ge et al., 1995; Steele et al., 2013). The conceptual model does not include potential moderators, such as ethnicity, which will be returned to.

The model is adjusted for a number of controls for the family and social context which may affect our key relationships of interest, including markers of socio-economic status that have been shown to predict variation in family interaction processes and child adjustment (Conger \& Donnellan, 2007; Conger \& Elder, 1994). They are further described in more detail below. Although the main part of our cross-lagged model is saturated, the whole model is not saturated, as the covariates we adjust for are time-varying.

We focus on the early years ( 3 to 5 years old), a critical developmental period which has often been overlooked by the literature on this subject. Because these analyses focus on mutual influences in the parent-parent and the parent-child relationships, this period of the life course is particularly interesting, as we know that early childhood relationships have long-lasting effects on childhood and adult adjustment.

\section{Data}

A recent, nationally representative prospective cohort study is used for this work. The Millennium Cohort Study (MCS) includes 18,818 children living in the UK at 9 months of age and born over a period spanning 2000-01 (Dex \& Joshi, 2005). The sample has a probability design and is clustered at the electoral ward level. The survey design over-sampled areas with high ethnic density, areas of high child poverty, and Northern Ireland, Scotland and Wales. The study mainly consisted of interviews with the main carer. At sweep 1, this was the mother in $98 \%$ of cases. A proxy interview with the main respondent was conducted if the resident partner could not be interviewed directly.

To date, four sweeps of data collection have been archived, when cohort members were aged about 9 months, 3, 5 and 7 years. Here we use data for ages 3 and 5 (sweeps 2 and 3). We focus on the pre-school data, since, for most children, the family is the main environment they spend time in and the major source of socialization in the pre-school period. The overall response rate for sweep 1 was $68 \%$, and following this response rates for sweeps 2 and 3 were $78 \%$ and $79 \%$, respectively. Final sample sizes were 18,818 children in sweep $1 ; 15,808$ at sweep 2; and 15,459 at sweep 3 (Hansen, 2008). Here we limit our sample for analysis to cohort members living with the same two parents at both age 3 and 5, with complete data on key variables (maternal mental health, child difficulties score, and parental relationship quality) available at both sweeps, producing a final sample size of 6,572 households.

As for all cohort studies, attrition is present and the households lost to follow-up were more likely to come from disadvantaged backgrounds than 
those retained in the study (data available on request). Survey weights to correct for cohort members having unequal probabilities of selection in the study due to the stratified and clustered sample design, as well as to take account of attrition between sweeps and unit non-response (Plewis, 2007) are applied in these analyses.

\section{Measures}

Maternal psychological distress was assessed using the six item (K6) Kessler Psychological Distress Scale (Kessler et al., 2002; Kessler \& Mroczek, 1994). This was administered using a computerassisted, self-completion form. Each parent was asked how often in the past 30 days they had felt: 'so depressed that nothing could cheer you up ', 'hopeless ', 'restless or fidgety', 'that everything you did was an effort', 'worthless', 'nervous'. Individuals scored four points for responding 'all of the time'; three points for 'most of the time'; two points for 'some of the time'; one point for 'a little of the time' and no points for 'none of the time'. The Kessler scale has good reliability and validity (Kessler et al., 2002; Kessler \& Üstün, 2004), and correlates with previously diagnosed depression and currently treated depression. Within our analytical sample, Cronbach's alphas indicated good internal consistency (Sweep 2: $\alpha=0.82$; Sweep 3: $\alpha=0.85$ ). We use the questions included in the survey to create a continuous score, with higher scores indicating higher distress levels.

To measure parental relationship quality, the Golombok Rust Inventory of Marital State (GRIMS) was selected. The scale is a 28 -item questionnaire designed to assess the quality of the relationship between a married or cohabiting couple (Rust, Bennun, Crowe, \& Golombok, 1986), asking respondents items such as 'my partner is usually sensitive to and aware of my needs' and 'sometimes I feel lonely even when I am with my partner', with responses ranging from strongly agree to strongly disagree. The GRIMS includes not only negative items (which would only tap into parental conflict), but also positive ones, constructing a more holistic description of the parents' relationship. Only four questions from the scale were available in the self-completion part of the age 3 and 5 sweeps, so we use these questions to create a continuous score, with higher scores indicating more conflict and poorer relationship quality. Cronbach's alphas indicated good internal consistency (Sweep 2: $\alpha=0.67$; Sweep 3: $\alpha=0.81$ ).

The Strengths and Difficulties Questionnaire (SDQ) is a behavioural screening questionnaire designed to measure psychological adjustment in 3-16 year olds (R. Goodman, 1997, 2001). It includes 20 items, some positive and others negative, where an item is a description of an attribute of the child's behaviour. The 20 items are divided into four scales of five items each: Hyperactivity/inattention (e.g. restless, overactive, cannot stay still for long); Conduct problems (e.g. often fights with other children or bullies them); Emotional symptoms (e.g. has many fears and is easily scared); Peer problems (e.g. is rather solitary, tends to play alone). The main carer indicates whether each item is: Not true; Somewhat true; or Certainly true of the child in question, and responses are scored 0,1 or 2, such that higher scores indicate more problematic behaviour. Responses across all scales are summed to derive the Total Difficulties Score, which can range from 0 to 40 . Here, we use this as a continuous score, with higher values indicating more problems. As a guide to interpretation, the SDQ defined cutoff scores are: normal (0-13 points), borderline (14$16)$, or abnormal (17 or above); the latter two categories may signal problems that require clinical intervention.

\section{Model variables}

The income earned by the resident partners was reported by the main respondent at all sweeps using a banded show card. It is important to note that this relates to the resident partners' income, not the overall household income, as other earners in the household were not included. It does, however, include any regular payments made by a nonresident parent to the resident carer. The variable used for modelling purposes is a continuous measure of parental income.

Questions on the highest educational qualifications achieved by the main carer were classed according to the National Vocational Qualification (NVQ) classification. Categories for analyses are: no qualifications, overseas qualifications only, NVQ 1 , NVQ 2, NVQ 3, NVQ 4, and NVQ 5. Roughly, an NVQ 5 is equivalent to a graduate degree; an NVQ 3 is equivalent to two A-levels. We could not further classify those with overseas qualifications (which make up about $1 \%$ of our sample), as further details were not asked in the survey. 
A series of questions asked of the main respondent aim to tap into the atmosphere in the home. These items were derived from the CHAOS scale (Matheny, Wachs, Ludwig, \& Phillips, 1995). The CHAOS scale is designed to assess the level of confusion and disorganization in the child's home environment, and is targeted for homes with infants and toddlers. In the Millennium Cohort, three questions from the CHAOS scale were included. The main respondent was asked whether they thought the following statements applied to their home: "the atmosphere in your home is calm", "it's really disorganised in your home" and "you can't hear yourself think in your home". Answers are on a five point scale and range from "strongly agree" to "strongly disagree". These three variables appeared to load on the same factor (sweep 2: Eigenvalue 1.04, factor loadings respectively $0.58,0.55,0.63$; sweep 3: Eigenvalue 1.07, factor loadings respectively $0.61,0.52,0.66)$, and therefore capture an underlying common construct, which we will refer to as "household chaos". We summed the three variables to give a score ranging from zero to twelve, with higher scores indicting a more chaotic home atmosphere.

\section{Methods}

Initial descriptive analyses, regressions and correlations were used to examine the stability in, and relations between, the 3 key variables at 2 data points.

To model intra-household dynamics between maternal mental health, child socio-emotional behaviour and parental relationship quality, we conducted a cross-lagged structural equation model, which allowed us to simultaneously estimate the nine sets of longitudinal relationships described above (see Figure 1). Analyses were restricted to two-parent households, in which the parents were continuously partnered across sweeps 2 and 3 (ages 3 and 5), with no missing data on any of the six key variables.
We conducted sensitivity analyses to explore whether hypothesised associations were affected by the inclusion of 540 ethnic minority households in our sample (or $7.5 \%$ of our final sample). Restricting the sample to White British participants did not significantly alter the results, and therefore we did not exclude the ethnic minority population from our final analyses. We also ran our models for male and female cohort members separately and found that, although there was some loss of statistical significance, likely due to reduced sample sizes, the direction and magnitude of effect sizes were similar for boys and girls. We therefore decided to run our final analyses on boys and girls together. Further sensitivity analyses were carried out by adding a measure of mental health at baseline (9 months) as one of the co-variates, including this measure in the model did not significantly improve model fit and led to over-adjustment with the mental health measures already present in the model.

Model fit was assessed using several goodnessof-fit criteria. The chi-square is highly sensitive to sample size and distributional assumptions ( $\mathrm{Hu} \&$ Bentler, 1995), so we used three other measures of model fit: the comparative fit index (CFI), the Tucker-Lewis index (TLI), and the root mean square error of approximation (RMSEA). The CFI and TLI range in value from 0 to 1 , with values greater than 0.9 indicating a good fit. RMSEA values range from 0 (perfect fit), to 1 (not acceptable). Values up to 0.05 are considered a good fit (Browne, Cudeck, Bollen, \& Long, 1993).

Models were adjusted for maternal age at birth, sex of the cohort member, maternal education (measured at age 3), and household income, household composition, and household chaos (all measured at ages 3 and 5). Descriptive statistics were weighted for non-response and the unequal probability of being sampled. All analyses were conducted using Stata (StataCorp, 2011). 


\section{Results}

\section{Descriptive results}

Table 1 describes our sample in terms of the model variables. We note that our sample is relatively advantaged, with a mean parental income of $£ 31,600$ at age 3 , and a mean maternal age at birth

of the cohort child of 30 years, likely due to the exclusion from our final sample of lone parents and households that experience parental separation.

Table 1. Means and proportion of the sample at cut-off point for selected variables

\begin{tabular}{|c|c|c|c|c|c|}
\hline & \multicolumn{2}{|c|}{ Age 3} & \multicolumn{2}{|c|}{ Age 5} \\
\hline & & & SD & & SD \\
\hline \multicolumn{2}{|c|}{ Cohort member's SDQ, mean score } & 8.61 & 4.73 & 6.33 & 4.39 \\
\hline \multicolumn{2}{|c|}{ Maternal Kessler, mean score } & 2.86 & 3.19 & 2.59 & 3.28 \\
\hline \multicolumn{2}{|c|}{ Golombok Rust Inventory mean score } & 4.47 & 2.88 & 4.79 & 3.00 \\
\hline \multicolumn{2}{|c|}{ Parental annual income, $£ 1000$ s } & 31.6 & 19.1 & 34.8 & 20.2 \\
\hline \multicolumn{2}{|c|}{ Maternal age at cohort member's birth, age } & 30.07 & 5.12 & - & - \\
\hline \multicolumn{2}{|c|}{ Cohort member's sex (female), \% } & 49.19 & - & - & - \\
\hline \multirow[t]{7}{*}{ Maternal education, \% } & None & 4.26 & - & - & - \\
\hline & Overseas & 1.23 & - & - & - \\
\hline & NVQ 1 & 5.59 & - & - & - \\
\hline & NVQ 2 & 25.78 & - & - & - \\
\hline & NVQ 3 & 16.59 & - & - & - \\
\hline & NVQ 4 & 37.08 & - & - & - \\
\hline & NVQ 5 & 9.47 & - & - & - \\
\hline
\end{tabular}

As shown in Table 2, regression analysis showed that in households where children had greater behavioural problems, mothers reported more symptoms of psychological distress, and more relationship problems, were reported to be more chaotic and tended to have lower incomes.
Table 3 displays the correlations among study variables that provided some tentative support for our hypotheses. Maternal psychological distress, parental relationship quality and child socioemotional behaviour are correlated. 
Table 2. Regression of age 5 outcome variables

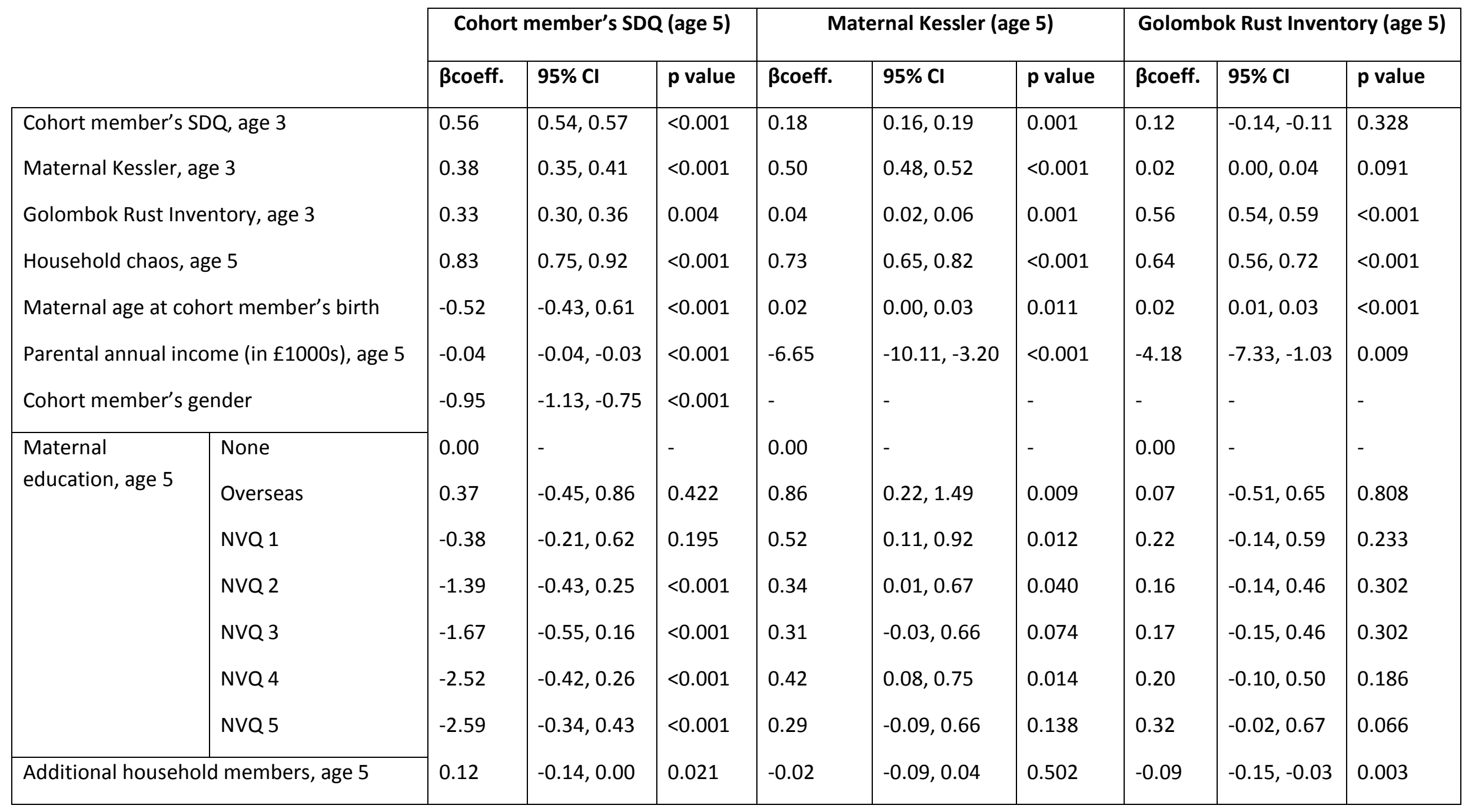


Table 3. Unadjusted correlations among variables in the models

\begin{tabular}{|l|l|l|l|l|l|l|l|}
\cline { 2 - 8 } \multicolumn{2}{c|}{} & \multicolumn{3}{c|}{ Age 3 } & \multicolumn{3}{c|}{ Age 5 } \\
\cline { 2 - 8 } & SDQ & Kessler & GRI & SDQ & Kessler & GRI \\
\hline Age 3 & SDQ & 1.00 & - & - & - & - & - \\
& Kessler & 0.46 & 1.00 & - & - & - & - \\
& GRI & 0.39 & 0.39 & 1.00 & - & - & - \\
\hline Age 5 & SDQ & 0.64 & 0.21 & 0.14 & 1.00 & - & - \\
& Kessler & 0.36 & 0.58 & 0.30 & 0.41 & 1.00 & - \\
& GRI & 0.31 & 0.28 & 0.60 & 0.35 & 0.38 & 1.00 \\
\hline
\end{tabular}

\section{Cross lagged models}

Our hypothesised model, shown in Figure 1, fitted the data well (CFI: 0.966; TLI: 0.905; RMSEA: 0.054). All except one of the coefficients for the cross-lagged paths were significant at the .01 or .05 level (using one-tailed tests) and were consistent with the reciprocity hypothesis. First, the correlations suggested the possibility of significant reciprocal effects between maternal psychological distress and child behaviour. Second, although the most robust correlational evidence of reciprocity was for maternal psychological distress and child behaviour, similar patterns of correlations also occurred for parental relationship quality with both child behaviour and maternal psychological distress. However, we did not find a significant feedback effect of parental relationship quality on child behaviour. Finally, there were robust auto-regressive lagged effects over time for all key variables, indicating continuity in these variables.

\section{Figure 1. Model results}

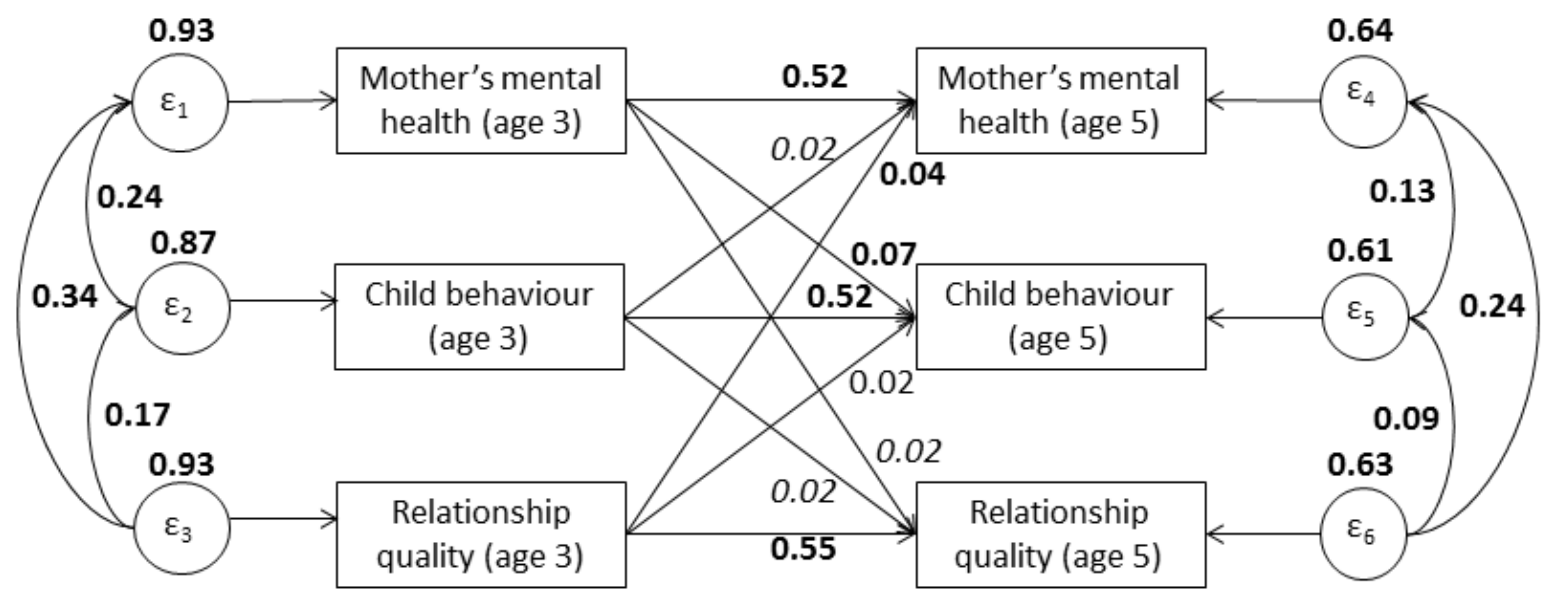

Notes. Standardised estimates: emboldening indicates statistical significance $p<0.001$; italics $p<0.05$. Model adjusts for maternal age at cohort member's birth, cohort member's age, cohort member's gender, household income, maternal educational level, household chaos, and maternal post-natal depression. 


\section{Conclusions}

Based on contemporary developmental psychology theories that emphasise interdependent family systems and mutual influence (Maccoby, 2003), we hypothesised that maternal psychological distress, parents' relationship quality and early childhood behavioural difficulties would be reciprocally linked over time. Results from the autoregressive, cross lagged model mostly provided support for this hypothesis. Briefly, we found evidence that maternal psychological distress when the child was aged three significantly predicted both early childhood behavioural difficulties and parental relationship quality when the child was aged five. Although effect sizes were smaller, early childhood behaviour also significantly predicted maternal psychological distress and parental relationship quality 2 years later. Parental relationship quality when the child was aged three predicted maternal psychological distress, but not child behaviour, when the child was aged five.

These results support studies indicating that maternal mental health is associated with childhood difficulties (Cummings \& Davies, 1994; Downey \& Coyne, 1990; Mensah \& Kiernan, 2010; Smith, 2004), and confirm that such correlation may extend to early childhood. Previous work focused on the uni-directional influence of maternal distress on child difficulties, with debates on which effect comes first, maternal distress or child difficulties. The present results indicate that this association involves reciprocal effects, and, rather than focusing on the "which comes first" issue, the focus should be on recognizing the bi-directional nature of maternal well-being and child difficulties.

Previous studies which considered the reverse relationship (child effects on parental well-being) have largely been focused on children with marked developmental problems or have examined how children may or may not be associated with certain parenting practices. The current study examined the interplay between maternal well-being and child difficulties during early childhood in a general population, and generate support for revised theorizing about the complex nature of parent- child relationships (Kerr \& Stattin, 2003).

Another important contribution of this study is to show the importance of considering relationships beyond the mother-child dyad. To do so, we included a measure of parental relationship quality in our models. Our results indicated that parental rela- tionship quality was influenced by earlier maternal mental health and child behaviour, and that the relationship with maternal mental health was reciprocal over time. In other words, parental relationship quality appeared to contribute to, and be influenced by, the context in which parent-child relationships occur. This finding further illustrates the interdependent nature of family relationships and linked family systems (e.g., couple and parentchild).

In evaluating the significance of these findings, it is helpful to consider the advantages and disadvantages of our study. First, the reciprocal model was evaluated using a prospective, longitudinal design involving repeated measures on two occasions. The availability of longitudinal data provided the opportunity to demonstrate the hypothesized reciprocal process. Second, the rich dataset available to us and the large sample size, allowed us to include controls on a number of variables such as gender, household socio-economic background, the presence of other household members, and a broader measure of the household environment. Third, we tested the reciprocal model in early childhood, a critical developmental period. Similar work has been tested at different periods of development, notably adolescence (Cui et al., 2007). Our study shows that the relationships which have been observed at adolescence are replicable at earlier developmental periods.

Although there are a number of methodological strengths of the present work, the study also has several limitations. First, due to the nature of our research question we were obliged to restrict our sample to stable two-parent families. Clearly, family instability will have an impact on all our key variables, and it was not possible to explore this here. Furthermore, although we made statistical adjustments for various aspects of the family context, we did not specifically analyse whether the relationships we observed varied according to the family context. For example, rates of both maternal depression and child adjustment problems tend to be higher among low-income, single-parent families than more advantaged, two-parent families (Curtis, Dooley, Lipman, \& Feeny, 2001; Offord, Boyle, \& Jones, 1987). This raises the question of whether our findings apply in both advantaged and disadvantaged contexts. In addition to focusing only on stable two-parent families, we further restricted our sample to observations with complete cases on 
key variables across the two sweeps. Given the disproportionate representation of attrition in disadvantaged households, it is likely that our findings are an under-representation of the strength of the relationships presented. Future research should test the generalisability of our findings, in particular whether they can be replicated in different socioeconomic contexts, or across different ethnic groups.

Second, the child behavioural problems were reported by mothers. This raises the possibility that mothers who experienced greater levels of psychological distress may have a tendency to perceive their children's problem behaviour to be more severe. However, studies in which maternal reports of child behaviour were compared with behavioural observations and teacher reports have not consistently found that depressed mothers are less accurate in assessing their child's behaviour than nondepressed mothers (Richters, 1992). Generally, studies have shown that mothers (depressed or not) provide reliable and accurate assessments of child psychological well-being and that depressed mothers are not significantly biased to misreport child symptoms compared to non-depressed mothers (Faraone, Biederman, \& Milberger, 1995; Querido, Eyberg, \& Boggs, 2001). Nonetheless, other sources of method variance (e.g., social desirability) may have inflated associations between maternal psychological distress and child behavioural difficulties.

Finally, there are questions about the size and practical significance of the reciprocal effects. Our large sample meant that we were able to capture small but statistically significant effects. Small ef- fects are not necessarily trivial, especially when they reflect an on-going process related to the wellbeing of individuals and families (see Rosenthal \& Rubin, (1979), for a discussion of the importance of small effects). This research literature includes a great deal of evidence that numerically small or moderate effects often translate into larger practical effects (Abelson, 1985; Lipsey, 1990; Rosenthal \& Rubin, 1982). Furthermore, while the size of our effects may be small, on a population level these relationships are nevertheless important. It is also important to remember that our effect sizes may be underestimated due to our selected sample, and therefore in reality these relationships might be larger. Therefore, observed reciprocal effects may have a substantial and practically significant impact on family functioning and child well-being, as they play out over the life-course.

Concluding, our results support the idea that maternal psychological distress and child behaviour are intertwined phenomena which do not play out in isolation from other family actors. Intervention programmes and policy should recognize the complicated nature of these reciprocal influences, and consider an integrated and dynamic family system. From a clinical standpoint, some treatment models still focus on individuals' symptoms and tend not to account for the contribution of family dynamics. For example, parent training programmes for managing externalizing behaviour in children are based on the notion that change in parent behaviour leads to change in child behaviour. The results of this study underscore the potential for enhancing such "unidirectional" treatment models by considering reciprocal, complex household dynamics.

\section{Acknowledgements}

We thank the Millennium Cohort Study (MCS) families for their time and cooperation, as well as the MCS team at the Institute of Education. The MCS is funded by the Economic and Social Research Council, UK. We would also like to thank the reviewers for their helpful comments on this paper, and Prof. Amanda Sacker for statistical advice. This work was partly funded by the ESRC International Centre for Lifecourse Studies in Society and Health (RES-596-28-0001). Laia Bécares was supported by an ESRC grant (ES/K001582/1) and a Hallsworth Research Fellowship.

\section{References}

Abelson, R. P. (1985). A variance explanation paradox: When a little is a lot. Psychological Bulletin, 97, 129132. http://dx.doi.org/10.1037/0033-2909.97.1.129

Anderson, K. E., Lytton, H., \& Romney, D. M. (1986). Mothers' interactions with normal and conductdisordered boys: Who affects whom? Developmental Psychology, 22, 604-609. http://dx.doi.org/10.1037/0012-1649.22.5.604 
Barkley, R. A., \& Cunningham, C. E. (1979). The effects of methylphenidate on the mother-child interactions of hyperactive children. Archives of General Psychiatry, 36, 201-208. http://dx.doi.org/10.1001/archpsyc.1979.01780020091010

Bartley, M. (1994). Unemployment and ill health: understanding the relationship. Journal of Epidemiology and Community Health, 48, 333-337. http://dx.doi.org/10.1136/jech.48.4.333

Belsky, J., \& Rovine, M. (1990). Patterns of marital change across the transition to parenthood: Pregnancy to three years postpartum. Journal of Marriage and the Family, 22, 5-19. http://dx.doi.org/10.2307/352833

Benzies, K. M., Harrison, M. J., \& Magill-Evans, J. (2004). Parenting stress, marital quality, and child behavior problems at age 7 years. Public Health Nursing, 21, 111-121. http://dx.doi.org/10.1111/j.0737-1209.2004.021204.x

Browne, M. W., Cudeck, R., Bollen, K. A., \& Long, J. S. (1993). Alternative ways of assessing model fit. In K. A. Bollen \& J. S. Long (Eds.), Testing Structural Equation Models (pp. 136-162). Beverly Hills, CA: Sage.

Cleaver, H., Unell, I., \& Aldgate, J. (1999). Children's Needs-Parenting Capacity: The impact of parental mental illness, problem alcohol and drug use, and domestic violence on children's development. London: The Stationery Office.

Collins, W. A., Maccoby, E. E., Steinberg, L., Hetherington, E. M., \& Bornstein, M. H. (2000). Contemporary research on parenting: the case for nature and nurture. American Psychologist, 55, 218-232. http://dx.doi.org/10.1037/0003-066X.55.2.218

Conger, R. D., Conger, K. J., Elder, G. H., Lorenz, F. O., Simons, R. L., \& Whitbeck, L. B. (1992). A family process model of economic hardship and adjustment of early adolescent boys. Child Development, 63, 526-541. http://dx.doi.org/10.2307/1131344

Conger, R. D., \& Donnellan, M. B. (2007). An interactionist perspective on the socioeconomic context of human development. Annual Review of Psychology, 58, 175-199. http://dx.doi.org/10.1146/annurev.psych.58.110405.085551

Conger, R. D., \& Elder, G. H. (1994). Families in troubled times: Adapting to change in rural America. New York: Walter de Gruyter.

Cui, M., Donnellan, M. B., \& Conger, R. D. (2007). Reciprocal influences between parents' marital problems and adolescent internalizing and externalizing behavior. Developmental Psychology, 43, 1544-1552. http://dx.doi.org/10.1037/0012-1649.43.6.1544

Cummings, E. M., \& Davies, P. T. (1994). Maternal Depression and Child Development. Journal of Child Psychology and Psychiatry, 35, 73-122. http://dx.doi.org/10.1111/j.1469-7610.1994.tb01133.x

Curtis, L. J., Dooley, M. D., Lipman, E. L., \& Feeny, D. H. (2001). The role of permanent income and family structure in the determination of child health in Canada. Health Economics, 10, 287-302. http://dx.doi.org/10.1002/hec.591

Dex, S., \& Joshi, H. (2005). Children of the 21 st century: from birth to nine months. Bristol: The Policy Press.

Dishion, T. J., \& Kavanagh, K. (2000). A multilevel approach to family-centered prevention in schools: Process and outcome. Addictive Behaviors, 25, 899-911. http://dx.doi.org/10.1016/S0306-4603(00)00126-X

Downey, G., \& Coyne, J. C. (1990). Children of depressed parents: an integrative review. Psychological Bulletin, 108, 50-76. http://dx.doi.org/10.1037/0033-2909.108.1.50

Elgar, F. J., Curtis, L. J., McGrath, P. J., Waschbusch, D. A., \& Stewart, S. H. (2003). Antecedent-consequence conditions in maternal mood and child adjustment: A four-year cross-lagged study. Journal of Clinical Child and Adolescent Psychology, 32, 362-374. http://dx.doi.org/10.1207/S15374424JCCP3203 05

Faraone, S. V., Biederman, J., \& Milberger, S. (1995). How reliable are maternal reports of their children's psychopathology? One-year recall of psychiatric diagnoses of ADHD children. Journal of the American Academy of Child \& Adolescent Psychiatry, 34, 1001-1008. http://dx.doi.org/10.1097/00004583-199508000-00009

Ge, X., Conger, R. D., Lorenz, F. O., Shanahan, M., \& Elder Jr, G. H. (1995). Mutual influences in parent and adolescent psychological distress. Developmental Psychology, 31, 406-419. http://dx.doi.org/10.1037/0012-1649.31.3.406

Goodman, R. (1997). The Strengths and Difficulties Questionnaire: a research note. Journal of Child Psychology and Psychiatry, 38, 581-586. http://dx.doi.org/10.1111/j.1469-7610.1997.tb01545.x

Goodman, R. (2001). Psychometric properties of the strengths and difficulties questionnaire. Journal of the American Academy of Child \& Adolescent Psychiatry, 40), 1337-1345. http://dx.doi.org/10.1097/00004583-200111000-00015

Goodman, S. H., \& Gotlib, I. H. (1999). Risk for psychopathology in the children of depressed mothers: a developmental model for understanding mechanisms of transmission. Psychological Review, 106, 458490. http://dx.doi.org/10.1037/0033-295X.106.3.458

Gould, N. (2006). Mental health and child poverty. York: Joseph Rowntree Foundation.

Hansen, K. (2008). Millennium Cohort Study first, second, and third surveys: a guide to the datasets. London: Institute of Education, University of London. 
Hauser-Cram, P., Warfield, M. E., Shonkoff, J. P., Krauss, M. W., Sayer, A., Upshur, C. C., \& Hodapp, R. M. (2001). Children with disabilities: A longitudinal study of child development and parent well-being. Monographs of the Society for Research in Child Development, 66(3, Serial N. 266), i-126.

Hay, D. F., Pawlby, S., Sharp, D., Asten, P., Mills, A., \& Kumar, R. (2001). Intellectual problems shown by 11-year-old children whose mothers had postnatal depression. Journal of Child Psychology and Psychiatry, 42, 871-889. http://dx.doi.org/10.1111/1469-7610.00784

Hu, L.-t., \& Bentler, P. M. (1995). Evaluating model fit. In R. H. Hoyle (Ed.), Structural Equation Modeling: Concepts, issues and applications. Thousand Oaks, CA: Sage.

Hudson, C. G. (2005). Socioeconomic Status and Mental Illness: Tests of the Social Causation and Selection Hypotheses. American Journal of Orthopsychiatry, 75, 3-18. http://dx.doi.org/10.1037/0002-9432.75.1.3

Jenkins, J., Simpson, A., Dunn, J., Rasbash, J., \& O'Connor, T. G. (2005). Mutual influence of marital conflict and children's behavior problems: Shared and nonshared family risks. Child Development, 76, 24-39. http://dx.doi.org/10.1111/i.1467-8624.2005.00827.x

Jenkins, R., Bhugra, D., Bebbington, P., Brugha, T., Farrell, M., Coid, J., . . Meltzer, H. (2008). Debt, income and mental disorder in the general population. Psychological Medicine, 38, 1485-1493. http://dx.doi.org/10.1017/S0033291707002516

Katz, L. F., \& Gottman, J. M. (1993). Patterns of marital conflict predict children's internalizing and externalizing behaviors. Developmental Psychology, 29, 940-950. http://dx.doi.org/10.1037/00121649.29.6.940

Katz, L. F., \& Woodin, E. M. (2002). Hostility, hostile detachment, and conflict engagement in marriages: Effects on child and family functioning. Child Development, 73, 636-652. http://dx.doi.org/10.1111/1467-8624.00428

Kerr, M., \& Stattin, H. (2003). Parenting of adolescents: Action or reaction? In A. C. Crouter \& A. Booth (Eds.), Children's influence on family dynamics: The neglected side of family relationships (pp. 223-228). Mahwah, New Jersey: Lawrence Erlbaum.

Kessler, R. C., Andrews, G., Colpe, L. J., Hiripi, E., Mroczek, D. K., Normand, S.-L. T., Walters, E. E., \& Zaslavsky, A. M. (2002). Short screening scales to monitor population prevalences and trends in non-specific psychological distress. Psychological Medicine, 32, 959-976. http://dx.doi.org/10.1017/S0033291702006074

Kessler, R. C., \& Mroczek, D. (1994). Final Versions of our Non-Specific Psychological Distress Scale. Survey Research Centre of the Institute for Social Research, University of Michigan. Ann Harbour.

Kessler, R. C., \& Üstün, T. B. (2004). The world mental health (WMH) survey initiative version of the world health organization (WHO) composite international diagnostic interview (CIDI). International Journal of Methods in Psychiatric Research, 13, 93-121. http://dx.doi.org/10.1002/mpr.168

Kiernan, K. E., \& Huerta, M. C. (2008). Economic deprivation, maternal depression, parenting and children's cognitive and emotional development in early childhood1. The British Journal of Sociology, 59, 783806. http://dx.doi.org/10.1111/i.1468-4446.2008.00219.x

Kiernan, K. E., \& Mensah, F. K. (2009). Poverty, maternal depression, family status and children's cognitive and behavioural development in early childhood: A longitudinal study. Journal of Social Policy, 38, 569-588. http://dx.doi.org/10.1017/S0047279409003250

Kiernan, K. E., \& Pickett, K. E. (2006). Marital status disparities in maternal smoking during pregnancy, breastfeeding and maternal depression. Social Science \& Medicine, 63, 335-346. http://dx.doi.org/10.1016/j.socscimed.2006.01.006

Lamb, M. E. (2004). The role of the father in child development. New York: John Wiley \& Sons.

Leerkes, E. M., \& Crockenberg, S. C. (2002). The development of maternal self-efficacy and its impact on maternal behavior. Infancy, 3, 227-247.http://dx.doi.org/10.1207/S15327078IN0302 7

Lipsey, M. W. (1990). Design sensitivity: Statistical power for experimental research. Newbury Park, CA: Sage.

Lovejoy, M. C., Graczyk, P. A., O'Hare, E., \& Neuman, G. (2000). Maternal depression and parenting behavior: A meta-analytic review. Clinical Psychology Review, 20, 561-592. http://dx.doi.org/10.1016/S0272-7358(98)00100-7

Maccoby, E. E. (2000). Perspectives on gender development. International Journal of Behavioral Development, 24, 398-406. http://dx.doi.org/10.1080/016502500750037946

Maccoby, E. E. (2003). Dynamic viewpoints on parent-child relations-their implications for socialization processes. In L. Kuczynski (Ed.), Handbook of dynamics in parent-child relationships (pp. 439-452). Thousand Oaks, CA: Sage.

Matheny, A. P., Wachs, T. D., Ludwig, J. L., \& Phillips, K. (1995). Bringing order out of chaos: Psychometric characteristics of the confusion, hubbub, and order scale. Journal of Applied Developmental Psychology, 16, 429-444. http://dx.doi.org/10.1016/0193-3973(95)90028-4

Mensah, F. K., \& Kiernan, K. E. (2010). Parents' mental health and children's cognitive and social development. Social Psychiatry and Psychiatric Epidemiology, 45, 1023-1035. http://dx.doi.org/10.1007/s00127-009-0137-y 
Mezulis, A. H., Hyde, J. S., \& Clark, R. (2004). Father involvement moderates the effect of maternal depression during a child's infancy on child behavior problems in kindergarten. Journal of Family Psychology, 18, 575-588. http://dx.doi.org/10.1037/0893-3200.18.4.575

Najman, J. M., Behrens, B. C., Andersen, M., Bor, W., O'CALLAGHAN, M., \& Williams, G. M. (1997). Impact of family type and family quality on child behavior problems: A longitudinal study. Journal of the American Academy of Child \& Adolescent Psychiatry, 36, 1357-1365.

http://dx.doi.org/10.1097/00004583-199710000-00017

National Institute of Child Health, \& the Human Development Early Child Care Network. (2005). Duration and developmental timing of poverty and children's cognitive and social development from birth through third grade. Child Development, 76, 795-810. http://dx.doi.org/10.1111/j.1467-8624.2005.00878.x

Oates, M. (1997). Patients as parents: the risk to children. British Journal of Psychiatry, Supplement 32, 2227.

Offord, D. R., Boyle, M. H., \& Jones, B. R. (1987). Psychiatric disorder and poor school performance among welfare children in Ontario. The Canadian Journal of Psychiatry/La Revue Canadienne de Psychiatrie, 32, 518-525.

Olsson, M. B., \& Hwang, C. (2001). Depression in mothers and fathers of children with intellectual disability. Journal of Intellectual Disability Research, 45, 535-543. http://dx.doi.org/10.1046/i.1365-2788.2001.00372.x

Papousek, M., \& von Hofacker, N. (1998). Persistent crying in early infancy: a non-trivial condition of risk for the developing mother-infant relationship. Child: Care, Health and Development, 24, 395-424. http://dx.doi.org/10.1046/j.1365-2214.2002.00091.x

Plewis, I. (2007). Non-response in a birth cohort study: the case of the Millennium Cohort Study. International Journal of Social Research Methodology, 10, 325-334. http://dx.doi.org/10.1080/13645570701676955

Querido, J. G., Eyberg, S. M., \& Boggs, S. R. (2001). Revisiting the accuracy hypothesis in families of young children with conduct problems. Journal of Clinical Child Psychology, 30, 253-261. http://dx.doi.org/10.1207/S15374424JCCP3002 12

Richters, J. E. (1992). Depressed mothers as informants about their children: a critical review of the evidence for distortion. Psychological Bulletin, 112, 485-499. http://dx.doi.org/10.1037/0033-2909.112.3.485

Rosenthal, R., \& Rubin, D. B. (1979). A note on percent variance explained as a measure of the importance of effects. Journal of Applied Social Psychology, 9, 395-396. http://dx.doi.org/10.1111/j.1559-1816.1979.tb02713.x

Rosenthal, R., \& Rubin, D. B. (1982). A simple, general purpose display of magnitude of experimental effect. Journal of Educational Psychology, 74, 166. http://dx.doi.org/10.1037/0022-0663.74.2.166

Rothbaum, F., \& Weisz, J. R. (1994). Parental caregiving and child externalizing behavior in nonclinical samples: a meta-analysis. Psychological Bulletin, 116, 55-74. http://dx.doi.org/10.1037/0033-2909.116.1.55

Rust, J., Bennun, I., Crowe, M., \& Golombok, S. (1986). The Golombok-Rust inventory of marital state (GRIMS). Sexual and Marital Therapy, 1, 55-60. http://dx.doi.org/10.1080/02674658608407680

Schoon, I., Hope, S., Ross, A., \& Duckworth, K. (2010). Family hardship and children's development: the early years. Longitudinal and Life Course Studies, 1, 209-222.

Singer, G. H., \& Floyd, F. (2006). Meta-analysis of comparative studies of depression in mothers of children with and without developmental disabilities. American Journal on Mental Retardation, 111, 155-169. http://dx.doi.org/10.1352/0895-8017(2006)111[155:MOCSOD]2.0.CO;2

Smith, M. (2004). Parental mental health: disruptions to parenting and outcomes for children. Child \& Family Social Work, 9, 3-11. doi: 10.1111/j.1365-2206.2004.00312.x http://dx.doi.org/10.1111/j.1365-2206.2004.00312.x

StataCorp, L. (2011). STATA, release 12.0. College Station, Texas: StataCorp LP.

Steele, F., Rasbash, J., \& Jenkins, J. (2012). A multilevel simultaneous equations model for within-cluster dynamic effects, with an application to reciprocal parent-child and sibling effects. Psychological Methods, 18, 87-100. http://dx.doi.org/10.1037/a0029316

Tamis-LeMonda, C. S., Shannon, J. D., Cabrera, N. J., \& Lamb, M. E. (2004). Fathers and mothers at play with their 2-and 3-year-olds: contributions to language and cognitive development. Child development, 75, 1806-1820. http://dx.doi.org/10.1111/j.1467-8624.2004.00818.x

Waschbusch, D. A. (2002). A meta-analytic examination of comorbid hyperactive-impulsive-attention problems and conduct problems. Psychological Bulletin, 128, 118-150. http://dx.doi.org/10.1037/0033-2909.128.1.118

Weissman, M. M., Warner, V., Wickramaratne, P., Moreau, D., \& Olfson, M. (1997). Offspring of depressed parents: 10 years later. Archives of General Psychiatry, 54, 932-940. http://dx.doi.org/10.1001/archpsyc.1997.01830220054009

World Health Organization. (2001). World Health Report 2001: mental health: new understanding, new hope. Geneva: World Health Organization. 